\title{
HAEMATOLOGICAL ALTERATIONS ACCOMPANYING FALCIPARUM AND VIVAX MALARIA- A STUDY FROM A TERTIARY CARE TEACHING HOSPITAL IN NORTH-EAST INDIA
}

\author{
Pranita Medhi', Niva Rani Dutta², Swagata Dowerah ${ }^{3}$
}

1 Professor, Department of Pathology, Jorhat Medical College and Hospital, Jorhat, Assam, India.

${ }^{2}$ Assistant Professor, Department of Pathology, Jorhat Medical College and Hospital, Jorhat, Assam, India.

${ }^{3}$ Assistant Professor, Department of Pathology, Silchar Medical College, Silchar, Assam, India.

\begin{abstract}
\section{BACKGROUND}

Malaria poses a major health issue in some of the most populated areas of the world in spite of intensive efforts to reduce its transmission. Malaria causing plasmodia are parasites of blood and hence Plasmodium infection expectedly induces haematological alterations.

The aim of the study is to evaluate and determine the various haematological alterations associated with malaria and their differences in cases of falciparum and vivax malaria.
\end{abstract}

\section{MATERIALS AND METHODS}

This prospective hospital-based cross-sectional study was conducted in a clinical haematology section of the Department of Pathology in a tertiary teaching hospital during the period of one year.

This study was undertaken in a tertiary care teaching hospital in North East India. The laboratory confirmed cases over a period of one year were included in the study. Giemsa stained thick and thin films were used for the diagnosis of malaria and species identification. Complete blood count was done using Sysmex 5-part analyser and peripheral blood smear was studied. ESR was determined manually in all the cases. The smears that showed malarial parasites were further studied for confirmation and identification of species. Smears were also reviewed for adequacy of platelets count and other haematological changes.

\section{RESULTS}

Results from the study showed $53(75.7 \%)$ cases of P. falciparum, $15(21.4 \%)$ cases of P. vivax and 2 cases (2.9\%) had mixed infection. The male-female ratio was $3.1: 1 ; 41.4 \%$ cases showed anaemia with haemoglobin level below $10 \mathrm{~g} / \mathrm{dL}$. Incidence of anaemia with haemoglobin below $10 \mathrm{~g} / \mathrm{dL}$ was slightly higher in P. falciparum malaria (41.5\%) than P. vivax malaria (40.0\%). ESR above $20 \mathrm{~mm}$ AEFH was observed in 32.8\% (23/70) of the total malarial cases. Leucopenia (below 4000/ $\mu \mathrm{L}$ ) was observed in 8 $(11.4 \%$ ) out of total 70 cases and leucocytosis (above $11,000 / \mu \mathrm{L}$ ) was seen in 4 patients $(5.7 \%)$ out of 70 cases. All 4 patients were having falciparum malaria. Relative lymphocytosis was seen in total $75.4 \%$ cases of falciparum malaria and $80 \%$ cases of vivax malaria. Monocytosis was found in $27.1 \%$ of malaria cases and eosinophil counts were normal in all the studied cases. Thrombocytopenia was noted in $45.7 \%$ (32/ 70) of cases in our study, out of which $54.7 \%$ had falciparum malaria.

\section{CONCLUSION}

Various haematological findings can help in early diagnosis of malaria, which enables the clinician to provide appropriate treatment in a timely manner. When used in combination with other clinical and microscopic findings these parameters could improve diagnosis of malaria, thereby helps in preventing the occurrence of major complications in these patients.

\section{KEY WORDS}

P. falciparum, Haematological Changes, Malaria, P. vivax.

HOW TO CITE THIS ARTICLE: Medhi P, Dutta NR, Dowerah S. Haematological alterations accompanying falciparum and vivax malaria- a study from a tertiary care teaching hospital in North-East India. J. Evolution Med. Dent. Sci. 2018;7(39):4286-4290, DOI: $10.14260 /$ jemds/2018/956

\section{BACKGROUND}

Malaria poses a major health issue in some of the most populated areas of the world in spite of intensive effort to reduce its transmission. It is a mosquito-borne infectious disease caused by intracellular protozoan parasite belonging to the genus Plasmodium. Five (05) species are recognised as pathogens of humans, namely P. falciparum, P. vivax, P. ovale, 'Financial or Other Competing Interest': None.

Submission 14-08-2018, Peer Review 07-09-2018,

Acceptance 14-09-2018, Published 24-09-2018.

Corresponding Author:

Dr. Niva Rani Dutta,

Department of Pathology,

Jorhat Medical College and Hospital,

Jorhat-785001, Assam, India.

E-mail: nivasarmah@gmail.com

DOI: $10.14260 /$ jemds $/ 2018 / 956$

\section{(c) $(1) \$$}

P. malariae and P. knowlesi. Out of these, P. falciparum is associated with most serious morbidity and mortality. The clinical and public health impact of malaria is geographically variable depending on the involvement of the parasite species and the intensity of transmission. In 2010, it has been estimated that half of the world's population (3.5 billion people) will live in malaria transmission area.(1) More than 100 countries in the world are considered malarious, and more than 2.4 billion of the world's populations are at risk. The worldwide annual incidence of malaria is estimated to be about 300 - 500 million cases. Malaria kills between 1.1 million to 2.7 million people annually, of which majority are children under five years.(2) In 2013, 0.88 million cases of malaria have been recorded and on suspected cases 128 million tests being conducted showing P. falciparum causing $53 \%$ and P. vivax causing $47 \%$ of the infections.(3) Around $40 \%$ of the global population residing in the South-East Asian 
region is at risk of malaria. In the South-East Asia region according to $\mathrm{WHO}$, the incidence of malaria in India accounted for $58 \%$ of cases.(3) As haemoparasites for the majority of their complex life cycle, Plasmodium infections expectedly induce haematological alterations. Some of the changes are species specific.

The haematological abnormalities that have been seen consistently associated with malaria include anaemia, thrombocytopenia and mild-to-moderate atypical lymphocytosis. Infrequently disseminated intravascular coagulation has also been reported.(4) There have been some other reported haematological abnormalities also which include leucopenia, neutropenia, leucocytosis, neutrophilia, eosinophilia and monocytosis. ${ }^{(5,6)}$

Fever with chills and rigor, pallor, splenomegaly and other clinical signs and symptoms are sensitive markers of malaria infection. But they lack specificity and positive predictive values, especially in areas where malaria is less prevalent $(7,8)$ and sometimes it may be difficult to differentiate from other viral or bacterial infections. (9) Laboratory diagnosis based on microscopic slide examination of peripheral blood and is considered as the gold standard for detecting malaria parasites. (10) However, it is timeconsuming, as it requires technical expertise and repeated smear examinations. During malarial infection some of the haematological changes such as anaemia, thrombocytopenia and leucocytosis or leucopenia are well recognised. Diagnostic values of these haematological changes may be obtained easily and can be applied as a useful measure in people living in malaria-endemic areas. This study aimed to evaluate and determine the various haematological alterations associated with malaria and their differences in cases of falciparum and vivax malaria.

\section{MATERIALS AND METHODS}

This prospective hospital-based cross-sectional study was undertaken in a clinical haematology section of the Department of Pathology in a tertiary teaching hospital during the period of one year. All the laboratory confirmed cases (smear positive) over a period of one year were included and studied for haematological changes.

Clinical history, demographic details, signs and symptoms were noted as per prefixed proforma. Venous blood in EDTA vacutainer was collected from the patient for diagnosis of malaria and haematological study before starting antimalarial treatment. Complete blood count was done using 5 parts fully automated Sysmex (XS-800i) analyser, peripheral blood smears were stained with Leishman stain and light microscopic examination was done under oil-immersion at a magnification x1000. Minimum of 200 fields (Oil immersion) were assessed before labelling a negative smear. Giemsa stained thick and thin smears were prepared. Thick smears were examined for rough estimation of parasite by observing average number of parasites per oil immersion field. Thin smears were examined for platelet count, identification of species and grading of parasitaemia. The grading and percentage of parasitaemia were done by counting schizonts, ring and amoeboid forms under oil immersion. ESR was determined manually in all the cases.

Anaemia and thrombocytopenia were labelled when haemoglobin $(\mathrm{Hb})$ was $<10.0 \mathrm{~g} / \mathrm{dL}$ and platelet counts were $<150,000 / \mu \mathrm{L}$ respectively. This study was approved by the Institutional Research and Ethics Committee.

\section{Statistical Analysis}

The data obtained were tabulated on Microsoft Excel spreadsheet, analysed and was expressed in terms of ratios and percentages. The comparison of various haematological parameters in P. falciparum and P. vivax malaria infection was tested using Chi-square test and when the expected frequencies are less than 5, Fisher's Exact test was applied. A probability value ( $p$-value) of less than 0.05 was considered statistically significant.

While comparing various haematological parameters between $P$. falciparum and P. vivax malaria infection, the cases which had mixed infection were not included in the statistical analysis.

\section{RESULTS}

Our study showed total 70 cases were diagnosed with malaria, 53 cases were of P. falciparum (75.7\%) [Fig. 1 and 2], 15 cases of P. vivax (21.4\%) [Fig. 3] and 2 cases (2.9\%) had mixed infection [Fig. 4]. The maximum number of cases comprising of $51.4 \%$ were in the age group of 21 - 30 years followed by $17.1 \%$ in the age group of $11-20$ years. The minimum age recorded was 6 years and the maximum age recorded was 50 years.

In all types of malaria, male predominance was observed. The male-female ratio was 3.1: 1. Majority of the patients presented with fever with chills and rigor (91.4\%). Other symptoms observed were the headache $(61.4 \%)$, malaise, body ache and arthralgia (42.9\%), giddiness (37.1\%), nausea and vomiting $(21.4 \%)$, pain abdomen (14.3\%); altered consciousness, loose stools were the other less frequent presenting symptoms. Irregular fever was commonest in falciparum malaria (34\%) and tertian fever was the commonest type in P. vivax malaria $(60 \%)$. No case of hyperpyrexia was observed in the present study.

of the 70 cases, only $30 \%$ showed systemic involvement. Haematopoietic system involvement was commonest, which manifested mostly as anaemia. Other organ systems involved were CNS involvement (8.6\%), hepatic involvement (7.1\%), gastrointestinal involvement $(4.3 \%)$ and renal involvement (2.8\%). Most of the serious manifestations were seen in falciparum malaria.

Out of the 70 cases studied, 29 cases (41.4\%) showed anaemia with the haemoglobin level below $10 \mathrm{~g} / \mathrm{dL}$. In our study, incidence of anaemia with haemoglobin below $10 \mathrm{~g} / \mathrm{dL}$ was slightly higher in P. falciparum malaria (41.5\%) than P.vivax malaria $(40.0 \%)$. While comparing haemoglobin value between P. falciparum and P. vivax, our study did not show significant statistical difference ( $p$-value $>0.05)$. However, the anaemia was more severe in falciparum than in vivax malaria with minimum recorded $\mathrm{Hb}$ level of $6 \mathrm{~g} / \mathrm{dL}$ in 2 cases [Table 1].

ESR above $20 \mathrm{~mm}$ AEFH was observed in 32.8\% (23 cases) of the total malarial cases, out of 23 cases only 3 cases (4.2\%) showed ESR between $51-100 \mathrm{~mm} \mathrm{AEFH.} \mathrm{In} \mathrm{this}$ study, there was no significant statistical difference of ESR between P. falciparum and P. vivax ( $p$-value $>0.05$ ) [Table 2].

A total leucocyte count of $4000-11,000 / \mu \mathrm{L}$ was seen in $83 \%$ cases of $\mathrm{P}$. falciparum and $80 \%$ cases of $\mathrm{P}$. vivax. Leucopenia (below 4000/ $\mu \mathrm{L}$ ) was observed in only 8 $(11.4 \%$ ) cases and leucocytosis (above $11,000 / \mu \mathrm{L}$ ) was seen in 4 patients $(5.7 \%)$ out of the total 70 cases, all 4 were suffering from falciparum malaria. This study did not show 
significant statistical difference in total leucocyte count between these two species ( $p$-value $>0.05$ ) [Table 3].

Percentage of neutrophils was between $40-60 \%$ in $60.3 \%$ of P. falciparum cases (32 patients) and $33.3 \%$ of P.vivax cases (5 patients). None of the patients had neutropenia in our study. Relative lymphocytosis was seen in total $75.4 \%$ of falciparum malaria (40 cases) and $80 \%$ of vivax malaria ( 12 cases). Lymphopenia below $20 \%$ was seen only in 3 cases $(5.7 \%)$. All 3 cases had P. falciparum malaria.

In this study, monocytosis was found only in 19 cases (27.1\%) out of total (70) malaria cases. Eosinophil counts were normal in all the studied cases.

In the present study, thrombocytopenia (platelet count $<150,000 / \mu \mathrm{L}$ ) was present in $45.7 \%$ of total malaria patients. Out of which $54.7 \%$ of cases (29 patients) were observed in P.falciparum malaria. The lowest count observed was $48,000 / \mu \mathrm{L}$, which was noted in a case of falciparum malaria. Our study showed significant statistical difference in platelet count between P. falciparum and P. vivax ( $p$-value $<0.05)$ [Table 4]. On the evaluation of the peripheral blood smear, $20 \%$ of the patients showed moderate degree of anisocytosis and poikilocytosis, which was mainly found in P. falciparum cases and only 20 (2.8\%) cases showed normoblasts indicating erythroid hyperplasia/ stimulation.

\begin{tabular}{|c|c|c|c|c|}
\hline $\mathrm{Hb}(\mathrm{g} / \mathrm{dL})$ & $\begin{array}{c}\text { P. falciparum } \\
n=53\end{array}$ & $\begin{array}{c}\text { P. vivax } \\
n=15\end{array}$ & $\begin{array}{c}\text { Mixed } \\
\mathrm{n}=2\end{array}$ & $\begin{array}{l}\text { Total } \\
\mathrm{n}=70\end{array}$ \\
\hline & No. (\%) & No. (\%) & No. (\%) & \\
\hline$<10$ & $22(41.5)$ & $6(40)$ & $1(50)$ & 29 \\
\hline$>=10$ & $31(58.5)$ & $9(60)$ & $1(50)$ & 41 \\
\hline \multicolumn{4}{|c|}{$\begin{array}{l}\text { Comparison between } P \text {. falciparum and } \\
\text { P.vivax }\end{array}$} & $\mathrm{p}$-value \\
\hline $\mathrm{Hb}(\mathrm{g} / \mathrm{dL})$ & P. falciparum & P. vivax & Total $=68$ & $\begin{array}{c}\text { (Chi-Square } \\
\text { Test) }\end{array}$ \\
\hline$<10$ & 22 & 6 & 28 & \multirow{2}{*}{\begin{tabular}{|c|}
0.916 \\
(Not \\
Significant)
\end{tabular}} \\
\hline$>=10$ & 31 & 9 & 40 & \\
\hline
\end{tabular}

Table 1. Showing Haemoglobin Levels in Study Group

\begin{tabular}{|c|c|c|c|c|}
\hline $\begin{array}{l}\text { ESR (mm } \\
\text { AEFH) }\end{array}$ & $\begin{array}{c}\text { P. falciparum } \\
n=53\end{array}$ & $\begin{array}{c}\text { P. vivax } \\
\mathrm{n}=15\end{array}$ & $\begin{array}{c}\text { Mixed } \\
n=2\end{array}$ & $\begin{array}{l}\text { Total } \\
\mathbf{n}=\mathbf{7 0}\end{array}$ \\
\hline & No. (\%) & No. (\%) & No. (\%) & \\
\hline $0-20$ & $36(67.9)$ & $10(66.7)$ & $1(50)$ & 47 \\
\hline $21-50$ & 15 (28.3) & $4(26.6)$ & $1(50)$ & 20 \\
\hline $51-100$ & $2(3.8)$ & $1(6.7)$ & & 3 \\
\hline \multicolumn{4}{|c|}{$\begin{array}{l}\text { Comparison between P. falciparum and } \\
\text { P.vivax }\end{array}$} & p-value \\
\hline $\begin{array}{l}\mathrm{ESR}(\mathrm{mm} \\
\mathrm{AEFH})\end{array}$ & P. falciparum & P. vivax & Total $=68$ & $\begin{array}{c}\text { (Chi- } \\
\text { Square } \\
\text { Test) }\end{array}$ \\
\hline$<20$ & 36 & 10 & 46 & \multirow{2}{*}{$\begin{array}{c}0.926 \\
\text { (Not } \\
\text { Significant }\end{array}$} \\
\hline$>=20$ & 17 & 5 & 22 & \\
\hline
\end{tabular}

\begin{tabular}{|c|c|c|c|c|}
\hline $\begin{array}{c}\text { Total } \\
\text { Leucocyte } \\
\text { count/ } \boldsymbol{\mu L}\end{array}$ & $\begin{array}{c}\text { P. falciparum } \\
\mathbf{n = ~ 5 3}\end{array}$ & $\begin{array}{c}\text { P. vivax } \\
\mathbf{n = 1 5}\end{array}$ & $\begin{array}{c}\text { Mixed } \\
\mathbf{n = 2}\end{array}$ & $\begin{array}{c}\text { Total } \\
\mathbf{n = 7 0}\end{array}$ \\
\hline$<4000$ & No.(\%) & No.(\%) & No.(\%) & \\
\hline $\begin{array}{c}4000- \\
11000\end{array}$ & $44(83)$ & $3(20)$ & & 8 \\
\hline$>11000$ & $4(7.6)$ & & $2(100)$ & 58 \\
\hline
\end{tabular}

\begin{tabular}{|c|c|c|c|c|}
\hline \multicolumn{4}{|c|}{$\begin{array}{l}\text { Comparison between P. falciparum and } \\
\text { P.vivax }\end{array}$} & \multirow{2}{*}{\begin{tabular}{|c}
$\mathrm{p}$-value \\
$\begin{array}{c}\text { (Fisher's } \\
\text { Exact Test) }\end{array}$
\end{tabular}} \\
\hline $\begin{array}{c}\text { Total } \\
\text { Leucocyte } \\
\text { Count } / \mu \mathrm{L}\end{array}$ & P. falciparum & P. vivax & Total $=68$ & \\
\hline$<4000$ & 5 & 3 & 8 & \multirow{2}{*}{$\begin{array}{c}0.361 \\
\text { (Not } \\
\text { Significant }\end{array}$} \\
\hline$>=4000$ & 48 & 12 & 60 & \\
\hline \multicolumn{5}{|c|}{$\begin{array}{c}\text { Table 3. Table showing Total Leucocyte Count in Study } \\
\text { Group }\end{array}$} \\
\hline
\end{tabular}

\begin{tabular}{|c|c|c|c|c|}
\hline $\begin{array}{l}\text { Platelet } \\
\text { Count } / \mu \mathrm{L}\end{array}$ & $\begin{array}{c}\text { P. falciparum } \\
n=53\end{array}$ & $\begin{array}{c}\text { P. vivax } \\
n=15\end{array}$ & $\begin{array}{c}\text { Mixed } \\
n=2\end{array}$ & $\begin{array}{l}\text { Total } \\
n=70\end{array}$ \\
\hline & No.(\%) & No.(\%) & No.(\%) & \\
\hline $\begin{array}{c}< \\
150,000 / \mu \mathrm{L} \\
\end{array}$ & $29(54.7)$ & $3(20)$ & & 32 \\
\hline $\begin{array}{c}150,000- \\
400,000 / \mu \mathrm{L}\end{array}$ & $24(45.3)$ & $12(80)$ & $2(100)$ & 38 \\
\hline $\begin{array}{c}> \\
400,000 / \mu \mathrm{L} \\
\end{array}$ & & & & \\
\hline \multicolumn{4}{|c|}{ Comparison between P. falciparum and P. vivax } & $\mathrm{p}$-value \\
\hline $\begin{array}{c}\text { Platelet } \\
\text { count } / \mu \mathrm{L}\end{array}$ & P. falciparum & P. vivax & Total $=68$ & $\begin{array}{c}\text { (Fisher's } \\
\text { Exact Test) }\end{array}$ \\
\hline$<150,000 / \mu \mathrm{L}$ & 29 & 3 & 8 & \multirow{2}{*}{$\begin{array}{c}0.0021 \\
\text { (Significant) }\end{array}$} \\
\hline $\begin{array}{c}>= \\
150,000 / \mu \mathrm{L}\end{array}$ & 24 & 12 & 60 & \\
\hline
\end{tabular}

\section{Table 4. Table showing Platelet Count in Study Group}

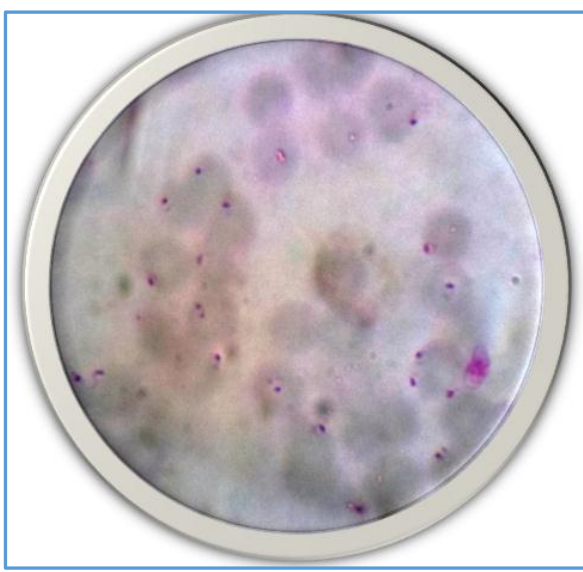

Figure 1. Showing Ring Trophozoites of $P$. falciparum in $R B C s$

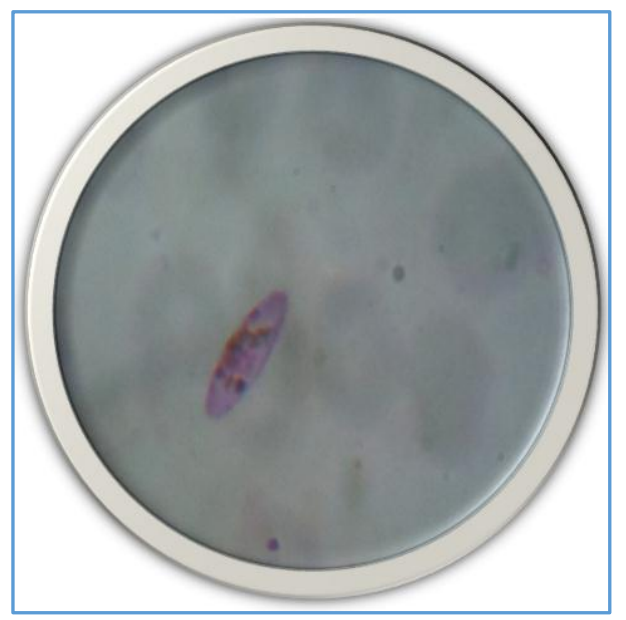

Figure 2. Showing Gametocyte of P. falciparum in Peripheral Blood 


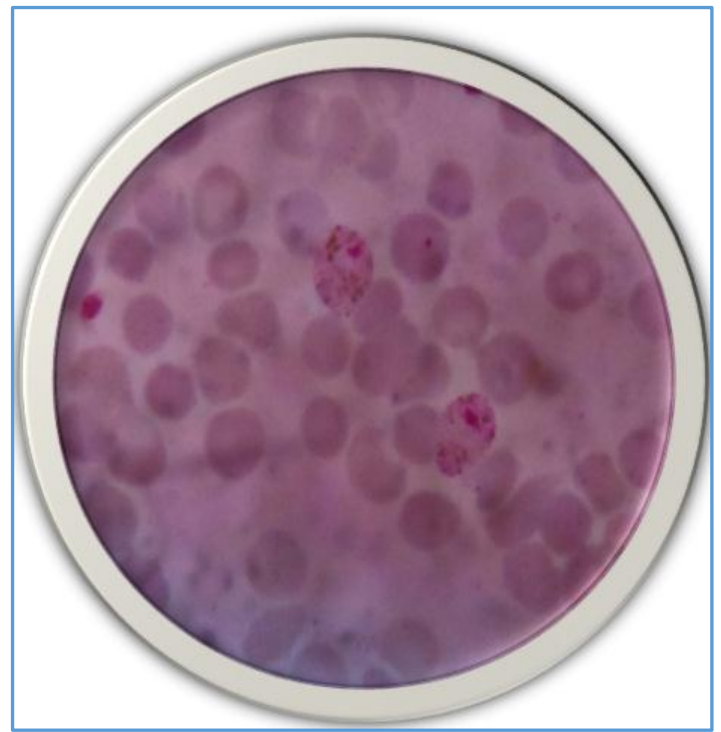

Figure 3. Showing P. vivax Infection in a background of Normocytic Normochromic Red Cells

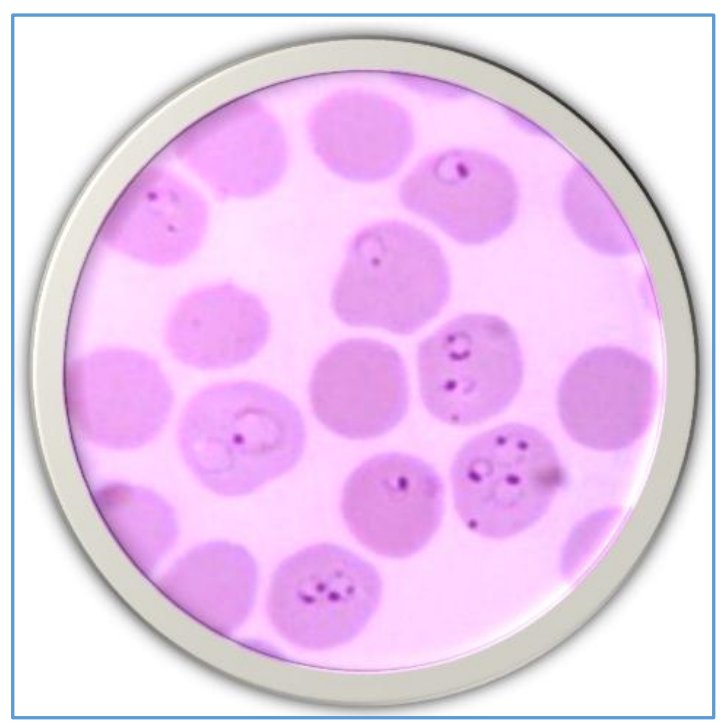

Figure 4. Showing Trophozoites of $P$. vivax and P. falciparum (Mixed Infection)

\section{DISCUSSION}

Results from the study showed out of total 70 cases diagnosed with malaria, (75.7\%) 53 cases were of P.falciparum, (21.4\%) 15 cases of P. vivax and 2 cases $(2.9 \%)$ had mixed infection. This shows that prevalence of P.falciparum is higher in this geographical location. In our study, male predominance was observed with a male-female ratio of 3.1: 1. Age wise distribution showed maximum number of cases (51.4\%) were in the adult age group 21 - 30 years followed by $17.1 \%$ in the age group of $11-20$ years. The minimum age recorded was 6 years and maximum age was 50 years. Majority of the patients presented with fever with chills and rigor (91.4\%) followed by headache (61.4\%).

Among the haematological parameters, anaemia is frequently observed finding in malaria and is reported to be most pronounced in P. falciparum infection. Our study showed the anaemia was more severe in falciparum than in vivax malaria with minimum recorded $\mathrm{Hb}$ level of $6 \mathrm{~g} / \mathrm{dL}$. This could be due to the varying preference of different malarial parasites to erythrocytes of varying ages. P.falciparum attack erythrocytes of all ages leading to high parasitic burden and profound anaemia, while P. vivax infects reticulocytes or young RBCs which are a small fraction of red cell pool. In our study, 29 cases (41.4\%) showed anaemia with the haemoglobin level below $10 \mathrm{~g} / \mathrm{dL}$. Incidence of anaemia with haemoglobin below $10 \mathrm{~g} / \mathrm{dL}$ was slightly higher in P. falciparum malaria (41.5\%) than P. vivax malaria (40.0\%). This study did not show statistically significant species variation in causing anaemia ( $p$-value $>0.05$ ). Incidence of anaemia in P. vivax infection in this study was $40.0 \%$, which was almost similar with the study carried out by Ranjini $\mathrm{C}$ et al, which showed anaemia in $40.74 \%$ of P.vivax infection. (11) Anaemia was normocytic normochromic in majority of cases, which is similar with the report of Facer and of Beales.(4,12) Only 4 cases $(5.7 \%)$ showed anaemia of microcytic hypochromic in type. The pathogenesis of anaemia in malaria is extremely complex and multifactorial. It is thought to be arising from a combination of haemolysis of parasitized erythrocytes, accelerated removal of both parasitized and non-parasitized erythrocytes, suppression of erythropoiesis and anaemia of chronic disease. $(4,13,14)$ Other factors causative to anaemia in malaria include decreased deformability of infected erythrocytes leading to increased cytoadherence in microvasculature, reticuloendothelial hyperplasia, splenic phagocytosis and/ or pooling due to which they have an increased rate of clearance from the circulation. (13)

In our study, $83 \%$ cases of $P$. falciparum and $80 \%$ cases of P. vivax cases showed normal leucocyte count. This was similar to the findings of Bashawri et al,(15) who noted a normal leucocyte count in majority of the patients (78.3\%). In our study, Leucopenia was observed only in 8 patients $(11.4 \%)$ out of total 70 . This study showed no statistically significant species variation in causing leucopenia ( $\mathrm{p}$-value > 0.05). In this study leucopenia was observed in $9.4 \%$ cases of P. falciparum and $20 \%$ of P. vivax infection, which was similar with the study of Ellis McKenzie F et al, 2005, which showed leucopenia in $10.7 \%$ cases of P. falciparum and $15.2 \%$ cases of P. vivax infections. (16) Leucopenia and neutropenia primarily reflects the state of hypersplenism.

Relative lymphocytosis was seen in total $75.4 \%$ cases of falciparum malaria and $80 \%$ cases of vivax malaria. Lymphopenia was seen in $5.7 \%$ of P. falciparum cases. Bashawri et al 2002 had noted lymphopenia in almost half the cases.(15) Though eosinophilia is common in parasitic infection, there was no eosinophilia in all the studied cases, which is similar with the report of Facer 1994.(4) Majority of patients had a normal monocyte count, which was also noted by Bashawri et al, 2002. (15) Monocytosis is a common finding in acute malaria as shown by the various studies. $(7,8,16)$ In our study, Monocytosis was observed only in (19 cases) $27.1 \%$ of cases. This study did not show any case of neutropenia.

Thrombocytopenia was noted in $45.7 \%$ of cases in our study, out of which $(54.7 \%)$ had falciparum malaria. Syam Sundar et al in 2013(17) noted thrombocytopenia in 69.9\% of cases. Bashawri et al in 2002(15) had also reported thrombocytopenia in more than half the patients. This study showed statistically significant species variation in causing thrombocytopenia ( $p$-value $<0.05$ ). In our study majority of patients had mild-to-moderate thrombocytopenia, only one 
case showed severe thrombocytopenia with a recorded level of $48,000 / \mu \mathrm{L}$.

Thrombocytopenia is a frequently observed finding in acute falciparum malaria, which is reported in various studies. In some areas, thrombocytopenia is often used as an indicator of malaria in patients presenting with Pyrexia of unknown origin. $(4,18)$ The precise mechanism behind thrombocytopenia is not clearly understood. Both the immunological as well as the non-immunological destruction of platelets have been implicated. The possible mechanism postulated are splenic pooling and oxidative stress causing premature platelet death and bone marrow dyspoiesis. There is also immune mediated lysis of circulating platelets by generation of anti-platelet antibodies. The latter is supported by finding malaria patients having elevated levels of plateletbound IgG. $(4,13,19)$ Another proposed mechanism is that platelets engulfing malarial parasites resulting in peripheral destruction of platelets. (20)

\section{CONCLUSION}

Malaria is one of the most common infections in Indian subcontinent, which affects mostly adults with male predominance. In our study, fever with chills and rigor and pallor are common clinical features. Among the haematological parameters studied, thrombocytopenia was the predominant haematological abnormality seen in malarial infection followed by anaemia. In a patient with febrile illness, observation of thrombocytopenia warrants careful search for malarial parasite. Severe complications are mostly associated with Falciparum infection. Various haematological alterations can help in early diagnosis of malarial complications and thus enables the clinician for providing appropriate treatment in a timely manner.. When used in combination with other clinical and microscopic findings, these parameters could improve diagnosis of malaria, thereby helping in preventing the occurrence of major complications in these patients.

\section{REFERENCES}

[1] Hay SI, Guerra CA, Tatem AJ, et al. The global distribution and population at risk of malaria: past, present and future. Lancet Infectious Diseases 2004;4(6):327-36.

[2] Taylor TE, Strickland GT. Malaria. In: Strickland's infectious disease. $4^{\text {th }}$ edn. London: Wiley 2006.

[3] WHO: World Malaria Report 2014. Geneva: 2014.

[4] Facer CA. Hematological aspect of malaria. In: Infection and hematology. Oxford: Butterworth Heinemann Ltd., 1994.
[5] Murphy GS, Oldfeild EC 3rd. Falciparum malaria. Infect Dis Clin North Am 1996;10(4):747-75.

[6] Jandle JH. Hemolytic anemias caused by infection of red blood cells. In: Blood. $2^{\text {nd }}$ edn. New York: Little Brown and Company, 1996.

[7] Maina RN, Walsh D, Gaddy C, et al. Impact of Plasmodium falciparum infection on haematological parameters in children living in Western Kenya. Malar J 2010;(9 Suppl 3):S4.

[8] WHO: New perspective, malaria diagnosis. Geneva: 2000.

[9] Lathia TB, Joshi R. Can hematological parameters discriminate malaria from non-malarious acute febrile illness in the tropics? Indian J Med Sci 2004;58(6):239-44.

[10] WHO: World Malaria Report 2010. Geneva: 2011.

[11] Ranjini C, Murgod R, Wilma DSCR, et al. Evaluation and comparison of hematological parameters between Vivax and Falciparum malaria. International Journal of Pharma and Bio Sciences 2012;3(4):1120-8.

[12] Beales PF. Anemia in malaria control: a practical approach. Ann Trop Med \& Parasitol 1997;91(7):7138.

[13] Perrin LH, Mackey LJ, Miescher PA. The hematology of malaria in man. Semin Hematol 1982;19(2):70-82.

[14] Clark IA, Chaudhri G. Tumour necrosis factor may contribute to the anemia of malaria by causing dyserythropoiesis and erythrophagoytosis. Brit J Haematol 1988;70(1):99-103.

[15] Bashawri LA, Mandil AA, Bahnassy AA, et al. Malaria haematological aspects. Annals of Saudi Medicine 2002;22(5-6):372-6.

[16] McKenzie EF, Prudhomme WA, Magill AJ, et al. White blood cell counts and malaria. The Journal of Infectious Diseases 2005;192(2):323-30.

[17] Sundar SB, Venugopal LS, Sivakumar, et al. Hematological and biochemical alterations in Malaria patients with clinical correlation in a tertiary care hospital. Int J Biol Med Res 2013;4(2):3139-42.

[18] Ankra-Badu GA. The diagnostic potential of the platelet count in acute malaria infection (abstract). King Fahd Hospital of the University, Al-Khobar, Saudi Arabia. Third Infectious Diseases Update, February 2000: p. 16-7.

[19] Essien EM. Medical hypothesis: the circulating platelet in acute malaria infection. Brit J Hematol 1989:72(4):589-90.

[20] Makkar RP, Mukhopadhyay S, Monga A, et al. Plasmodium vivax malaria presenting with severe thrombocytopenia. Braz J Infect Dis 2002;6(5):263-5. 